\title{
CLASES PARADIGMÁTICAS EN LA FORMACIÓN DEL PLURAL DE LOS SUSTANTIVOS
}

\author{
Annette Calvo Shadid
}

\begin{abstract}
RESUMEN
En este trabajo se analiza la formación del plural de los sustantivos de acuerdo con el modelo morfológico de palabra y paradigma. Se presentan dos tipos de modelos: la operación cero y la sufijación, los cuales están condicionados por ciertas variables lingüísticas, a saber, la cualidad del sonido que se presenta en posición final de la palabra, si esta es patrimonial, si es de uso común y si es conocida o no.
\end{abstract}

\begin{abstract}
The plural formation of nouns according to the morphological model word and paradigm is analized in this article. Two types of morphological processes are presented: zero operation and suffixation. These processes are conditioned by certain linguistic variables such as the quality of the word-final sound and whether or not the word is of longstanding in the language and widely known.
\end{abstract}

\section{Introducción}

\subsection{Estudios previos}

El tema de la marcación de la categoría del plural de los sustantivos presenta una extensa bibliografía, basada en diversos enfoques teóricos ${ }^{1}$.

Dentro de los estudios tradicionales, se puede citar la Real Academia Española (1920: 18-20). En esta gramática, se establecen reglas de formación del plural de acuerdo con dos variantes:

-es: con sustantivos terminados en consonante y en vocal acentuada que no sea -é, con algunas excepciones como papás, chacós, rondós, maravedís (junto con maravedies y maravedises).

$-s: \quad$ con sustantivos terminados en vocal inacentuada y en -é acentuada (-é). 
Además, reconoce que hay sustantivos "que no consienten alteración alguna en el plural" (1920: 18), como las palabras terminadas en -s: Carlos, crisis, dosis, etc.

Para las palabras de origen extranjero terminadas en una consonante que el castellano no usa ordinariamente como final, la Real Academia reconoce que hay muchas "anomalías" pero que, siguiendo la regla general, deben hacer el plural en -es.

Muchos autores siguen las reglas de formación de plural que establece la Academia. Sin embargo, reconocen que hay poca regularidad en los sustantivos terminados con vocal acentuada, pues varían entre $-e s$ y $-s^{2}$.

Para los extranjerismos terminados en consonante, algunos reconocen el uso más generalizado de la variante $-s$ o de $\emptyset^{3}$.

Se han propuesto otras teorías para explicar la formación del plural, las cuales tratan de eliminar las excepciones, o de suprimir las variantes.

Entre ellos, los estudios de tipo generativo transformacionales han propuesto la existencia de un solo morfema de plural para todos los sustantivos: $-s$. Para explicar las alternancias, se han propuesto dos teorías: la primera fue dada por Foley (1967: 486-93), la cual supone que toda palabra terminada en consonante o en vocal acentuada tiene una $e$ subyacente; ésta, por una regla de apócope, se suprime en singular pero permanece en plural.

Saltarelli (1970: 89-96), en oposición a la teoría anterior, propone una regla de epéntesis, por lo cual agrega una $e$ a la forma $-s$ correspondiente al plural. Para este autor, en castellano, no existe una $e$ subyacente, sino una inserción de la $e$ epentética al morfema de plural.

Otro tipo de estudios, como el de Sánchez Corrales (1984), pretende eliminar dichas excepciones presentando dos categorías de sustantivo sobre la base de la marcación del paradigma número: nombres con un solo tipo de tema (carné, número, popurrí, esquí, caries, martes, tórax, crisis) y nombres con dos temas: uno corto, que se usa para el singular (jarandae, alhelie, cruce, lápice). El marcador del plural es $-s$, y se manifiesta como -s o como cero, de acuerdo con las siguientes reglas:

Para hacer la formación del plural, se parte del singular como base: las palabras que presentan tema corto agregan el sufijo -s (popurrís, esquís) o cero, si el tema corto termina en -s (martes, caries, dosis, virus).

Los nombres con dos temas marcan el singular por medio del tema corto (jarandá, alhelí, etc.) y para el plural, al tema largo se le sufija el exponente $-s$ (jarandae $+s$ : jarandaes, alhelie + s: alhelies, etc.).

\subsection{Propósito de la investigación}

De acuerdo con la variación observada en el uso de los formativos de plural de los sustantivos, la autora realizó un análisis cuantitativo con el fin de establecer la distribución de las variantes ${ }^{4}$.

La interpretación de ese estado de variación se observó sobre la base de los planeamientos teóricos del modelo palabra y paradigma. 


\section{Marco teórico}

En el presente estudio se utilizó el modelo morfológico de palabra y paradigma, tal y como ha sido expuesto por Matthews (1970-75, 1972, 1979).

Según este autor (1979: 77), palabra y paradigma es el modelo tradicional de descripción de categorías morfosintácticas que se entrecruzan. En él, la palabra es la unidad central que está formada por un elemento léxico más una serie de propiedades gramaticales que forman un marco o matriz dentro del cual puede establecerse el paradigma de un lexema.

Este enfoque cuestiona el principio de las señales discretas o aisladas que son la base del modelo elementos y colocación, en el cual se asignan todas las propiedades distintivas de una palabra a cada uno de los formativos que los componen, del mismo modo como se ordenan las secuencias de segmentos en una cláusula.

Para el modelo de palabra y paradigma (Matthews 1979: 154-5), las propiedades y los formativos no siempre se corresponden. Un morfo individual es, en la mayoría de los casos, muy ambiguo y poco identificador, y su función específica solo aparece dentro de la palabra. Además, los rasgos de identificación de un elemento pueden superponerse, incluir o coincidir con los que se identifican a otro ${ }^{5}$.

Las propiedades morfosintácticas se conciben en este modelo como abstracciones de palabras tomadas en su totalidad y no como segmentos basados en su composición fonológica, lo cual constituye una característica de elementos y colocación (cfr. Matthews 1970-75: 110-1, 116).

Esto implica que los morfemas no se organizan secuencialmente como en el modelo anterior, sino que son propiedades de unidades mayores, y los diferentes exponentes se identifican por medio del paradigma.

De acuerdo con esto, Matthews (1970-75: 112) supone que cualquier propiedad o grupo de propiedades puede activar un número indeterminado de procesos sucesivos dentro de la misma derivación.

Se considera que el modelo palabra y paradigma es muy apropiado para describir las derivaciones en la formación del plural en castellano, ya que es un modelo de descripción de lenguas flexivas (cfr. Matthews 1972 y Hockett 1954).

En este sentido, se considera aplicable al castellano, y aquí se utiliza para expresar la propiedad de plural por formativos distintos.

\section{Clases paradigmáticas en la formación del plural}

De acuerdo con los resultados obtenidos en la formación del plural, en esta categoría se pueden establecer dos tipos de procesos: la operación cero 6 y la sufijación.

\subsection{Clases de palabras que prefieren la operación cero}

Los porcentajes más altos de preferencia por este proceso son: las palabras terminadas en consonante $-s$ precedida de vocal inacentuada (-vs), como tesis y crisis, y las terminadas en consonante $-s$ precedida de vocal inacentuada más $k$ (-vks), como tórax y ántrax: 


\section{Cuadro 1}

Clases de palabras que prefieren la operación cero de plural (términos porcentuales)

Entornos

Vocal inacentuada $+\mathrm{s}$

Vocal inacentuada $+\mathrm{k}+\mathrm{s}$ vs

99 vks

81.8

Sin embargo, se observó que este proceso es utilizado frecuentemente en otros contextos. Por ejemplo, esta variante se aplica con frecuencia en palabras no patrimoniales. Los términos de origen extranjero que se usaron siempre presentaban una frecuencia mucho más alta de plural con la operación cero que las palabras patrimoniales. Tales fueron los casos de los términos extranjeros terminados en $-\mathrm{y}$, con las consonantes $-\mathrm{n}$, -r y, especialmente con [ $\mathrm{t}$ ] $]$.

\section{Cuadro 1.1}

Uso de la operación cero de plural en palabras no patrimoniales terminadas con consonante (términos porcentuales)

$\begin{array}{lcccccccc}\text { Consonante } & -\mathrm{p} & -\mathrm{t} & -\mathrm{k} & -\mathrm{b} & -\mathrm{n} & -\mathrm{r} & -\mathrm{t} f & -\mathrm{y} \\ \text { Oper. cero } & 24 & 33 & 26 & 9 & 36 & 30 & 30 & 21\end{array}$

Los términos que arrojaron los resultados anteriores fueron:

$-p$ : clip, stop

$-t$ : caset, vermut, déficit, superávit

$-k:$ frac, bistec, coñac

$-b:$ club

$-n:$ eslogan

$-r$ : estándar

$-\mathrm{t} f:$ suich, cloch

$-y$ : convoy

Por otro lado, en las palabras terminadas con vocal acentuada, se observó un porcentaje relativamente alto de la operación cero de plural.

\section{Cuadro 1. 2}

Uso de la operación cero de plural en palabras terminadas con vocal acentuada (términos porcentuales)

Vocal acentuada

Porcentajes

$\begin{array}{lllll}-1 & -u ́ & -e ́ & -o ́ & \text {-á } \\ 13 & 17 & 9 & 22 & 20\end{array}$


El uso frecuente de esta variante, principalmente ante las vocales -á, -ó, corresponde probablemente a que muchas de las palabras utilizadas con estas vocales no eran conocidas por la mayor parte de los informantes. Por ejemplo, los términos utilizados con la vocal final -á fueron, a saber, tirrá, cubá, atarrá, agrá, y los terminados en -ó, buró, bongó y rondó.

Es probable que exista alguna correlación entre uso de esta operación de plural y el hecho de que para muchos de los informantes estas palabras fueran desconocidas o de uso no muy común.

\subsection{Clases de palabras que prefieren el proceso de su fijación}

Dentro de este proceso, se observó preferencia por dos formativos: -s y -es.

\subsubsection{Clases de palabras que prefieren el formativo $-s$}

Se da preferencia por este formativo en las palabras que terminan en vocales inacentuadas (v) como casa, conde, jersey, pueblo, las terminadas en vocales [-altas] acentuadas (-é, -ó, -á) como pie, poró, atarrá, las que terminan en consonante oclusiva sorda, como clip, caset y bistec, y las terminadas en diptongo con $-w$, como show.

\section{Cuadro 2}

Clases de palabras que prefieren la variante $-s$ de plural (términos porcentuales)

$\begin{array}{llllllllllll}\text { Entornos } & \mathrm{e} & \mathrm{a} & \mathrm{o} & \mathrm{i} & \mathrm{e} & \mathrm{o} & \mathrm{a} & \mathrm{p} & \mathrm{t} & \mathrm{k} & \mathrm{w} \\ \text { Vocal inacentuada } & 100 & 95.5 & 89.9 & 60.6 & - & - & - & - & & & \\ & - & - & - & & & & & & & & \\ \text { Vocal -alta acentuada } & - & - & - & - & 84.4 & 45.2 & 40 & & & & \\ & - & - & - & - & & & & & & & \\ \text { Consonante oclusiva sorda } & - & - & - & - & - & - & - & 62.1 & 53.1 & 46.2 \\ - & - & - & - & - & - & - & - & - & - & - & 66.7\end{array}$

Es importante señalar que los datos presentados difieren un tanto de las reglas de formación del plural formuladas antriormente, las cuales, en general, anotan que tanto las palabras terminadas con vocal acentuada como las terminadas en consonante hacen el plural con -es.

Sin embargo, en este análisis se observa que hay una tendencia mucho mayor de formar el plural con $-s$ en las palabras terminadas en vocal [-alta] acentuada $(-o ́,-e ́,-a ́)$, y en las terminaciones en consonante oclusiva sorda.

En estas últimas, la variación puede aplicarse por el hecho de que, en castellano, las palabras patrimoniales nunca terminan en consonante oclusiva, con excepción de la - $d$ (la cual no es oclusiva en posición final, sino fricativa o aproximante). 
Las palabras utilizadas en el cuestionario cuya terminación tenía este tipo de consonante eran todas de origen extranjero, como se observó anteriormente en el análisis de la operación cero de plural:

-p: $\quad$ clip, estop [no registradas en Corominas (1980-83)].

- $t$ : caset, vermut, déficit, superávit (no registradas en Corominas, con excepción de vermut, 1925).

$-k \quad$ frac (registrada en 1914).

Esto podría explicar que el hablante percibiera las palabras anteriores como extranjeras debido a su extructura silábica, puesto que en castellano los fonemas oclusivos sordos no se dan en posición final de palabra y que, por lo tanto, no hiciera el plural normalizado en -es para estos casos, sino principalmente en $-s \mathrm{y}$, con una frecuencia un poco menor, con la operación cero.

Como se puede observar, algunas de las palabras terminadas en $-p,-t,-k$ no están registradas aún en Corominas, y las que lo están tienen una fecha de incorporación bastante reciente (a mediados del S. XIX o ya entrado el S. XX).

Por esta razón, podría concluirse que a mayor antigüedad de la palabra en el castellano, más se ajusta a las reglas del idioma, y a menor antigüedad se da más rechazo o mayor dificultad de incorporación a las reglas patrimoniales.

\subsubsection{Clases de palabras que prefieren el formativo -es}

Estos sustantivos son los que terminan en vocal acentuada más consonante fricativa sorda (v́x, v́s) como reloj y raíz, en vocales [+altas] acentuadas (-í, -ú) como maní, urrú, en consonante oclusiva sonora $(-b,-d)$ como club y pared, en consonante sonante $(-l,-r,-n)$ como cárcel, estándar y diván, en vocal acentuada + t' (-v́t'), como clotch y suich, y en diptongo con $-j$ como rey y convoy.

\section{Cuadro 3}

Clases de palabras que prefieren la variante -es de plural (términos porcentuales)

\section{Entornos}

Voc. acent. + cons.

fri. sorda

Voc. altas acentuadas

Consonante sonante

Cons. oclus. sonora

Vocal acentuada $+\mathrm{t}$

Diptongo con - $\mathrm{j}$

$\begin{array}{rr}\text { V́X } & \text { V́s } \\ 93.3 & 89.4 \\ - & - \\ - & -\end{array}$

í

ú

62.5

48.1

-

1

$r$

19

$96.2^{-}$
79.8
44.7 
En relación con las palabras terminadas en - $t \int$ es importante anotar que, aunque se observa un porcentaje mayor de uso en -es $(45.5 \%)$ que en los otros formativos $(30.3 \%$ con operación cero y $24.2 \%$ con $-s$ ), los dos ítemes por separado presentan resultados un tanto diferentes:

\section{Cuadro 4}

Distribución de variantes de plural en palabras terminadas con -t' (términos porcentuales)

Variantes

\begin{tabular}{lllll}
\hline Consonante $-t^{\prime}$ & op. $\varnothing$ & $-\mathrm{s}$ & -es & Total \\
suich & 18 & 24 & 58 & 100 \\
cloch & 45.5 & 24.20 & 30.3 & 100 \\
\hline
\end{tabular}

Para suich se prefiere el plural en -es (suiches) y para cloch se prefiere la operación cero (cloch), pero sin despreciar la variante -es (cloches).

La causa de esta diferencia podría ser que el plural -es en suiches esté ya lexicalizado, y aún no en cloches.

Con respecto a las palabras terminadas con $-j \mathrm{y}-w$ en diptongo, el segmento $-j$ prefiere los plurales en -es (66.7\%) y el segmento - $w$ los prefiere en -s (66.7\%). Una posible explicación es que el único ítem utilizado con -w fue show, palabra extranjera cuya forma plural shows está prácticamente lexicalizada.

Con el segmento -y se utilizaron dos ítemes: rey y convoy, los cuales presentaron los siguientes resultados:

\section{Cuadro 5}

Distribución de las variantes de plural en palabras terminadas con -j (términos porcentuales) variantes

\begin{tabular}{lllll}
\hline Segmento $-\mathrm{j}$ & op. $\varnothing$ & $-\mathrm{s}$ & -es & Total \\
rey & - & - & 100 & 100 \\
convoy & 21 & 46 & 33 & 100 \\
\hline
\end{tabular}

Como es claro, el plural de rey, que es una palabra patrimonial, se hizo en -es (reyes) en todos los casos, mientras convoy, que es una palabra extranjera, mostró preferencia por el plural en -s (convoys), pero sin despreciar el plural en -es (convoyes).

Estas clases paradigmáticas confirman que la variante de plural usada por una mayor cantidad de entornos es -es, luego $-s$ y, por último, la operación cero.

En otras palabras, el proceso más utilizado para marcar la propiedad de plural, en castellano, es la sufijación, y el formativo más productivo es -es. 


\section{Conclusiones}

Algunos autores reconocen que existe mucha variación en el uso de los formativos de plural. En la presente investigación se ha podido demostrar que la distribución de estos formativos presenta, efectivamente, una amplia variación lingüística; sin embargo, ésta es sistemática y cuantificable.

En este sentido, se observó la frecuencia de esta variación y se organizó en clases paradigmáticas, de acuerdo con el modelo morfológico de palabra y paradigma.

Según este modelo, se puede afirmar que la formación del plural analizada presenta dos tipos de procesos morfológicos: la operación cero y la sufijación.

De acuerdo con esto, se encontraron algunas diferencias entre las clases paradigmáticas que prefieren el proceso de sufijación y las reglas gramaticales de formación del plural en castellano.

Tales diferencias se dan principalmente en las palabras terminadas con vocal acentuada y en los términos de origen extranjero, los cuales, dependiendo quizás de su grado de aclimatación en la lengua, o del tipo de sonido que presente en posición final, mostrarán preferencia por el uso de la operación cero, de $-s$ o de -es. Por ejemplo, los que terminan en oclusiva sorda prefieren el uso de -s, tales son los casos de clip, clips, y frac, fracs, entre otros. Estos casos difieren de las reglas de formación de plural en castellano, las cuales dicen que las palabras terminadas tanto en vocal acentuada como en consonante, hacen el plural en -es.

En relación con la operación cero de plural, además de las palabras que usan regularmente este formativo en castellano (ver cuadro 1), se aplica con frecuencia en palabras no patrimoniales terminadas también en consonante (ver cuadro 1.1).

Por esta razón, se ha concluido que, cuanto más antigüedad tenga la palabra en el castellano, más se ajusta a las reglas del idioma, y a menor antigüedad se da más rechazo o mayor dificultad de incorporación a las reglas patrimoniales.

Los resultados de las palabras terminadas con vocal son muy significativos, debido a que se observó que el rasgo altura parece influir en la preferencia por uno y otro sufijo. Las vocales [+altas] $(-i,-\hat{u})$ presentan una tendencia mayor a hacer el plural en -es, mientras que las [altas] $(-a ́,-o ́)$ prefieren el plural en $-s$. En muchos casos, se observa una alta frecuencia de la operación cero de plural, principalmente con las palabras terminandas también en - $a$ y en - $o$ (ver cuadro 1.2). Para estos casos, se concluye que es probable que las variables conociminto de la palabra o si esta es o no es de uso común, aunque se conozca, tengan que ver con la selección de la marcación cero de plural. Es decir, cuanto mayor sea el conocimiento que se tiene de la palabra, más fácilmente se adaptará a las reglas de formación del plural prescritas.

\section{Notas}

1.

2.

C Cfr. Bello (1847-58: 30), García de Diego (1951: 101), Henríquez Ureña (1949: 623), Seco (1960: 21), Real Academia Española (1973-79: 184), De la Peña (1985: 70), Alcina y Blecua (1975-79: 537), Carratalá (1980: 69). 
3. Real Academia Española (1973-79: 181), Arroyo (1971: 55), Lorenzo (1971: 56), Carratalá (1980: 68).

4. La muestra se recogió en el cantón de Curridabat, provincia de San José, y se entrevistaron 33 sujetos, manteniendo las proporciones de sexo, nivel de instrucción y grupos de edad. La variable nivel de instrucción se estratificó de acuerdo con tres niveles: primaria, secundaria y universitaria. La edad se delimitó de acuerdo con tres generaciones: I- de 25 a 35 años, II- de 36 a 55 años, III- de 56 años en adelante.

5. Cfr. Matthews (1979: 150-1) para observar un ejemplo de esta ambigüedad.

6. La operación cero (u operación de identidad) es una operación cuya entrada es idéntica a la salida.

\section{Bibliografía}

Alcina, J. y Blecua, J. M. (1975) 1979. Gramática española. Barcelona: Ariel.

Arroyo, V. M. 1971. El habla popular en la literatura costarricense, San José: Editorial de la Universidad de Costa Rica.

Bello, A. (1847) 1958. Gramática de la lengua castellana. Buenos Aires: Sopena.

Carratalá, E. 1980. Morfosintaxis del castellano actual. Barcelona: Labor.

Corominas, J. 1980-83. Diccionario crítico-etimológico castellano e hispánico. Madrid: Gredos.

De la Peña, R. 1985. Gramática teórica y práctica de la lengua castellana. México: Editorial de la Universidad Autónoma de México.

Foley, J. 1967. "Spanish plural formation”. Language. 46: 486-93.

García de Diego, V. 1951. Gramática histórica española. Madrid: Gredos.

Henríquez, U. P. 1949. Gramática castellana. Buenos Aires: Losada.

Hockett, Ch. 1954. "Two models of grammatical description". Word. 10: 210-31.

Lorenzo y C., E. 1971. El español en ebullición. Madrid: Gredos.

Lyons J. 1970. Nuevos horizontes de la lingüística. Madrid: Paraninfo.

(ed.) 1972. Inflectional Morfology: A theorical study based on aspects of Latin verb conjugation. Cambridge: Cambridge University Press. 
Matthews, P. H. 1970. “Evolución de la morfología en los últimos años”. En: Lyons J. (ed.). 1979. Morfología: introducción a la teoría de la estructura de la palabra. Madrid: Paraninfo.

Real Academia Española. 1920. Gramática de la lengua castellana. Madrid: Perlado, Páez y Compañía.

(1973) 1979. Esbozo de una nueva gramática de la lengua española. Madrid: EspasaCalpe S.A.

Sánchez, V. M. 1994. "La categoría morfosintáctica número en el sustantivo español”. Revista de Filología y Lingüística de la Universidad de Costa Rica. 20(1): 155-68. 